\title{
Behaviour of Pottos and Angwantibos
}

\author{
Magdalena S. Svensson and Averee M. Luhrs
}

\section{Introduction}

Studies on the behaviour of the African lorisiforms are scarce, but there are clear morphological, ecological and behavioural differences between the robust pottos (Perodicticus spp.) and the smaller, gracile angwantibos (Arctocebus spp.). Pottos have a wide distribution across the African rainforest zone, while angwantibos are restricted to the forests of western equatorial Africa. African lorisiforms are not as obviously gregarious as some of their diurnal primate relatives and have thus often been described as solitary animals. This description does not mean these animals do not exhibit any social behaviour - as Charles-Dominique (1977a) wrote, solitary is not the opposite of social, but of gregarious. Indeed, increased research attention and improved methods have slowly revealed an extensive repertoire of nocturnal primate social behaviour. In this chapter, we review existing research on social behaviour, mating and parental care, feeding and food acquisition, as well as positional and defensive behaviour in pottos and angwantibos. We also highlight their major differences and recommend areas for future research.

\section{General Social Behaviour}

Both pottos and angwantibos have been previously described as being mostly solitary animals. CharlesDominique (1977a) reported that central pottos (Perodicticus edwardsi) spent over 95 per cent of the observed time alone in Gabon. Ambrose (2013) reported that the golden angwantibo (Artocebus aureus) foraged alone for 96 per cent of the observed time, also in Gabon. Pottos have been described as exhibiting a dispersed single-male/multi-female social structure (Dixson, 1995), as well as a dispersed single-male/single-female social structure with the possibility of monogamous pairing (O'Mara et al., 2012; Pimley et al., 2005b). Both Pimley et al. (2005b) and Luhrs et al. (2018) found that spatial proximity $(<20 \mathrm{~m})$ between individuals of $P$. edwardsi was common. Pimley et al. (2005b) hypothesised that the high rate of gregariousness in $P$. edwardsi in Mount Kupe, Cameroon related to patches of high-quality fruit trees and the associated insects. Luhrs et al. (2018) hypothesised that anthropogenic activity with associated increase in patches of fruits and insects may facilitate increased social behaviour. As of 2019, angwantibos have been little studied. Charles-Dominique (1977a) reported that $A$. aureus proved impossible to capture, resulting in little to no data on home range and social structure. Jewell and Oates (1969a) reported handcapturing multiple Calabar angwantibos $(A$. calabarensis) in Nigeria and managed to keep and observe several of these individuals in an outdoor cage. Pimley (2009) reported on sightings of angwantibos during surveys at the Iko Esai Forest, Nigeria. In 2018, A. Luhrs recorded 15 sightings of angwantibos in 13 observations in the Oban region of Cross 
River National Park, Nigeria (Figure 17.1). It is possible that these animals exhibit a locally clumped distribution. Although observational data are still sparse, the available evidence suggests angwantibos share similar social behaviours with pottos. Jewell and Oates (1969a) describe angwantibos in captivity as readily interacting and sharing favourable sleeping sites within the enclosure.

Like many strepsirrhines, both pottos and angwantibos rely heavily on olfactory communication through both urine and glandular secretions (Luhrs et al., 2018; Nekaris, 2013; Oates, 1984; Pimley, 2003; Pimley et al., 2005b). Thus, much of their social interaction is conducted through indirect means. Charles-Dominique (1977a) described urine-marking by pottos as a possible means of social communication. Pottos have been described to leave urine trails on large supports in their territory where conspecifics are likely to encounter them. Direct interactions between conspecific pottos often include urine and glandular secretions, suggesting olfaction is important for both direct and indirect interaction and communication.

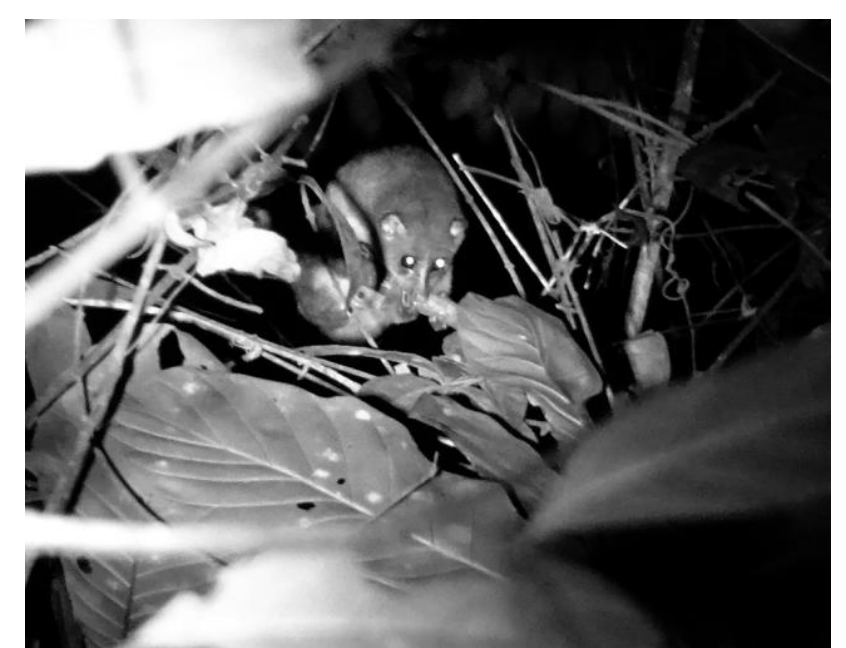

Figure 1. Perodicticus edwardsi in Angola. Photograph by E. Bersacola

\section{Reproduction}

Charles-Dominique (1977a) described 'male-following' courtship behaviour in which a male potto repeatedly enters a female's home territory and follows her for several days. Following this, CharlesDominique describes episodes of allogrooming, with 'active licking' and rubbing behaviour. Pimley (2003) and Pimley et al. (2005b) described mating in pottos ( $n=7$ events) preceded by allogrooming and followed by the male and female adopting a dorsal-ventral position, with the male generally suspended from the female on a branch. Allogrooming between individuals may include a 'genitalscratching marking' behaviour described by Manley (1974), in which the male scratches a specialised scrotal gland and subsequently rubs the female's fur. It is likely that glandular secretions and olfactory communication play an important role in allogrooming between pottos. Charles-Dominique (1977a) reported that births in pottos in Gabon occur in August to January, while Pimley (2003) reported that births seems to occur year-round in pottos in Cameroon. In angwantibos, there does not appear to be a mating season. Instead, mating may immediately follow births, which occur throughout the year (Charles-Dominique, 1977a; Jewell and Oates, 1969b; Oates, 2011). Allogrooming appears to be important for courtship and mating in angwantibos. Angwantibos have been observed performing a 
unique 'passing-over' behaviour, in which the male climbs over the female while rubbing his scrotal gland on her fur, likely marking her with olfactory secretions (Charles-Dominique, 1977a; Manley, 1974).

\section{Parental Behaviour}

Pottos and angwantibos both give birth on a branch, after which the neonates climb onto the mother's fur, clinging to the ventral area (Ambrose, 2013; Charles- Dominique, 1977a; Jewell and Oates, 1969a; Kingdon, 2015; Oates, 2011; Svensson et al., 2018). From three to eight days following the birth, the mother will leave the infant parked on a branch while she continues to forage, retrieving it only at the end of the night. This has been noted for both species, although the angwantibos sometimes carry their infants for longer. When older, the infant angwantibos begin to cling to the mother's fur dorsally (Ambrose, 2013; Charles-Dominique, 1977a; Jewell and Oates, 1969a; Kingdon, 2015). In captivity, female pottos have been observed to care for only healthy neonate pottos that are able to cling to a branch or to their mother after birth (Buckanoff et al., 2006). Juvenile A. calabarensis stay with their mother for some months after they have been weaned, and contact is maintained by high-pitched clicking calls (Kingdon, 2015). Pottos begin to accompany the mother during foraging at the age of about 3-4 months, when weaning and dietary conditioning begin (Charles-Dominique, 1977a). Pottos at this age continue to attempt to cling to their mother or may follow them closely behind. Luhrs et al. (2018) reported observations of a juvenile eastern potto ( $P$. ibeanus) and its mother in Kibale National Park, Uganda. During these mother- juvenile observations, there were repeated instances of allogrooming, sniffing, licking, rubbing, clasping and general contact. Luhrs et al. (2018) also observed the juvenile attempting to cling both ventrally and dorsally to its mother, despite being nearly equivalent to her in size. If clinging was rejected, the juvenile potto followed the mother closely as she foraged, occasionally breaking off and exploring surrounding habitat. The juvenile in this case exhibited a wide range of postural behaviours and a much higher rate of activity than the adult. Frederick (1998) reported observations of paternal care of an infant potto in captivity. The adult male potto spent a significant proportion of its time engaging in social behaviour with the infant, such as following, grooming and play. Similar observations of captive adult male pottos grooming and following infants have been reported by Cowgill $(1969,1974)$.

\section{Feeding Behaviour}

When foraging, pottos and angwantibos may hold their heads low, close to the branch, in a unique nose-down posture, utilising their strong sense of smell to locate food (Oates, 2011). Oates (1984) noted this posture may be particularly useful for the detection and consumption of ants and exudates, while also detecting the olfactory signals of conspecifics. Pottos appear to be omnivorous, consuming insects, exudates, fruits and occasional small vertebrates. While gum-feeding behaviour has been observed in wild pottos (Oates, 1984), the relative importance of exudates in the diet of these animals remains unclear. The frequency and amount of gum consumed by each potto species is not known. 
Luhrs et al. (2018) reported observations of $P$. edwardsi and $P$. ibeanus appearing to gouge on the bark of trees, similar to 'wounding' behaviour observed in the heavily exudativorous Asian slow lorises (Nycticebus spp.) (Nekaris et al., 2010a). Oates (1984) reports multiple observations of the sister species $P$. potto near, or present on, trees known to exude gums. Cowgill (1969) reported that captive pottos also often consumed birds. Indeed, the careful nose-down foraging behaviour of pottos has been suggested as a method for the capture of sleeping birds and other small vertebrates. In contrast to the omnivorous pottos, wild observations of angwantibos suggest a diet composed primarily of slow-moving noxious insects, like caterpillars (Charles- Dominique, 1977a; Jewell and Oates, 1969a; Oates, 1984; Sanderson, 1940). Charles- Dominique (1977a) reported observations of $A$. aureus regularly massaging insect prey prior to consumption, which may be a unique behavioural adaptation that functions to remove irritating hairs or spines. Charles-Dominique (1977a) also reported observing this 'prey-massaging' in young angwantibos unable to independently capture insect prey, suggesting it may be an innate behaviour in these animals.

\section{Locomotion and Positional Behaviour}

In contrast to the rapid clinging and leaping of the sympatric Galagidae, both pottos and angwantibos exhibit a slow climbing and grasping style of locomotion, although both can move quickly when necessary (Jewell and Oates, 1969a). Like other lorisiforms, neither pottos nor angwantibos leap, but instead exhibit careful, deliberate locomotion, adeptly climbing with very little disturbance to surrounding vegetation (Figure 17.2). Both angwantibos and pottos possess special adaptations for this lifestyle, including convergent vision and highly adducted big toes and thumbs, which allow them to grasp vegetation with a powerful pincer-like grip (Nekaris, 2013). Pottos use a wide variety of substrates in both primary and secondary forest (Luhrs et al., 2018; Nekaris, 2013; Pimley, 2003), though they generally appear to prefer larger branches in medium to higher forest strata (Bersacola et al., 2015; Luhrs et al., 2018; Oates, 1984). Pottos exhibit a range of postures and locomotion behaviours. Given their uniquely adapted pincer-like hands, pottos are able to bridge between large gaps in the substrate by firmly grasping a branch or twig of the destination tree and carefully pulling it towards themselves, with limited disturbance of surrounding vegetation (Charles-Dominique, 1977a; Poindexter and Nekaris, 2017b). In contrast, the body and hands of the angwantibo are not adapted for larger substrates. As a result, angwantibos tend to remain in the lower forest strata, using the finer vegetation such as small branches and lianas as supports in the undergrowth below $5 \mathrm{~m}$ (Bearder and Honess, 1992; Bearder et al., 2008b; Charles- Dominique, 1977a; Kingdon, 2015). In Gabon, Charles-Dominique (1977a) reported that $A$. aureus was limited primarily to tree-fall zones with understory growth and abundant lianas. Angwantibos have been occasionally observed at heights up to $15 \mathrm{~m}$ (Charles-Dominique, 1977a; Jewell and Oates, 1969a). Angwantibos may not be able to bridge between large gaps in the habitat. Charles-Dominique (1977a) reported that angwantibos did not exhibit the same path-choice abilities as the pottos and suggested that angwantibos may have poorer vision than pottos. Both pottos and angwantibos do occasionally come to the ground to forage, travel between close habitat patches or as a defence mechanism when threatened (Ambrose, 2013; Luhrs et al., 2018; Nekaris, 2013). When 
faced with predators or other threats, both pottos and angwantibos have a unique defensive behaviour. They both adopt a defensive nose-down position, in which their limbs become fully extended and rigid. Pottos direct their neck, which has a unique scapular shield, towards the threat, while thrusting their bodies and growling (Nekaris, 2013; Pimley, 2003). The angwantibos tuck their heads under their body, with the hindquarters raised, and will rapidly bite from under their armpit (Kingdon, 2015; Oates, 2011). The wild predators of angwantibos and pottos are not known with certainty, but may include viverrids, snakes and large birds of prey (Charles-Dominique, 1977a; Oates, 2011; Pimley, 2003; Svensson et al., 2018).

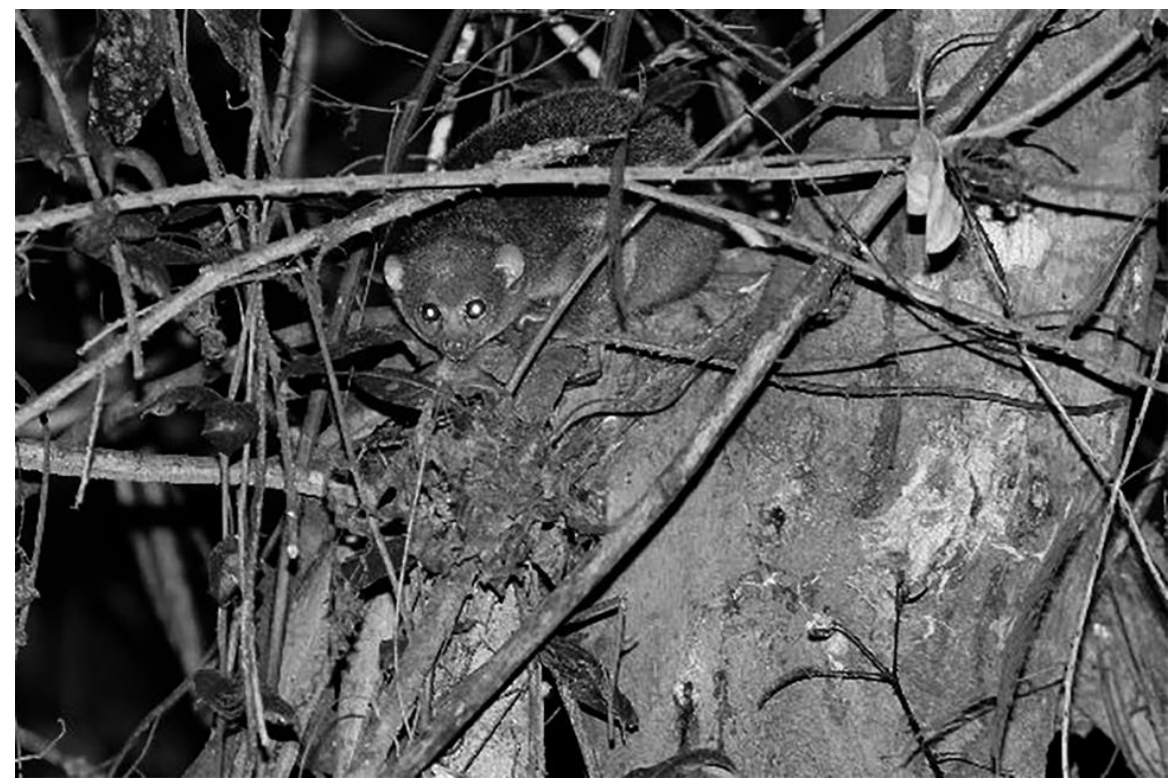

Figure 2. Arctocebus calabarensis in Nigeria Photograph by A. Luhrs.

\section{Vocalisations}

The African lorisiforms are considered relatively silent primates (Bearder et al., 2003; Nekaris et al., 2007; Oates, 1984; Pimley and Bearder, 2013). Audible vocal behaviour has been recorded in both wild and captive populations (Ambrose, 2013; Charles- Dominique, 1977a; Jewel and Oates, 1969a; Luhrs et al., 2018; Oates and Ambrose, 2013). In pottos, long-distance calls are likely too high-pitched to be audible to human ears, but a high-pitched whistling vocalisation has been reported in wild $P$. ibeanus in Kenya (Luhrs et al., 2018). Captive pottos have also been recorded to make these whistles, seemingly as a social spacing mechanism (Buckanoff et al., 2006; Cowgill, 1969; Nekaris, 2013). Epps (1974) reported six different vocalisation used in captive pottos, classified either as contact calls or used when the pottos displayed their defence postures. Vocalisations in angwantibos have only been studied in captivity. Angwantibos produce a hissing call when distressed, a groan-like call when threatened and a clicking call shared between mothers and infants (Ambrose, 2013; Charles-Dominique, 1977a; Jewell and Oates, 1969a; Oates and Ambrose, 2013). Research on other nocturnal primates, including Asian lorises, has suggested that many of these animals may be communicating in the ultrasonic range, thus inaudible to the human ear. Future research should investigate the possible presence of ultrasonic communication in pottos and angwantibos. 


\section{Suggestions for Future Research}

Many questions surrounding the behaviour and ecology of pottos and angwantibos remain unanswered. African species have remained relatively under-studied by the scientific community. The details of potto and angwantibo social structure, mating behaviour, parental care and diet remain unknown. Future studies on pottos and angwantibos should aim to uncover the frequency and quantity of consumption for each food type, particularly plant exudates for pottos and extent of insectivory in angwantibos. As of 2019 , no radio telemetry studies on angwantibos and on two potto species have been conducted. Future research should focus on uncovering the unique behavioural attributes of these animals through extensive long-term wild observation. Both pottos and angwantibos exist in areas subject to rapid habitat change. Given the perceived limited dispersal capability of these taxa, habitat fragmentation may pose a serious risk to their long-term survival. Increased research on angwantibo and potto range and niche will thus be essential to monitor the population trends and identify possible risks to them in the future.

\section{References}

Ambrose, L. (2013). Arctocebus aureus - Golden angwantibo. In T. M. Butynski, J. Kingdon \& J. Kalina, eds., Mammals of Africa (Volume II: Primates,). London: Bloomsbury Publishing, pp. 402-403.

Bearder, S. K., \& Honess, P. E. (1992). A Survey of Nocturnal Primates and Other Mammals in Korup National Park, Cameroon. Wildlife Conservation International, New York, 40.

Bearder, S., Oates, J. F. \& Groves, C. P. (2008). Arctocebus aureus. The IUCN Red List of Threatened Species 2008: e.T2053A9211012. http://dx.doi.org/10.2305/IUCN.UK.2008.RLTS.T2053A9211012.en. Downloaded on 11 June 2018.

Bearder, S. K., Ambrose, L., C. Harcourt, Honess, P., Perkin, A., Pimley, E., Pullen, S. \& Svoboda, N. (2003). Species-typical patterns of infant contact, sleeping site use, and social cohesion among nocturnal primates in Africa. Folia Primatologica, 74, 337-354.

Bersacola, E., Svensson, M. S. \& Bearder, S. K. (2015). Niche partitioning and environmental factors affecting abundance of strepsirrhines in Angola. American Journal of Primatology, 77, 11791192.

Buckanoff, H. D., Frederick, C. \& Weston Murphy, H. (2006). Hand-rearing a potto Perodicticus potto at Franklin Park Zoo, Boston. International Zoo Yearbook, 40(1), 302-312.

Charles-Dominique, P. (1977). Ecology and behaviour of nocturnal primates: prosimians of equatorial West Africa. Columbia University Press. 
Cowgill, U. M. (1969). Some observations on the prosimian Perodicticus potto. Folia Primatologica, 11(1-2), 144-150.

Cowgill, U. M. (1974). Co-operative behaviour in Perodicticus. Prosimian biology, 261-272.

Dixson, A. F. (1995). Sexual selection and the evolution of copulatory behavior in nocturnal prosimians. In L. Alterman, G. A. Doyle and M. K. Izard, eds., Creatures of the Dark . Springer, Boston, MA. pp. 93-118.

Epps, J. (1974). Social interaction of Perodicticus potto kept in captivity in Kampala, Uganda. In R. D. Martin, G. A. Doyle and A. C. Walker, eds., Prosimian biology. London: Duckworth. pp. 233244.

Frederick, C. (1998). Observations of paternal care in Perodicticus potto at the Cincinnati Zoo and Botanical Garden. Folia Primatologica, 69(5), 312-317

Jewell, P. A. \& Oates, J. F. (1969a). Ecological observations on the lorisoid primates of African lowland forest. Zoologica Africana, 4(2), 231-248.

Jewell, P. A. \& Oates, J. F. (1969b). Breeding activity in prosimians and small rodents in West Africa. Journal of Reproduction and Fertility, 6, 23-38.

Kingdon, J. (2015). The Kingdon field guide to African mammals. London: Bloomsbury Publishing.

Luhrs, A. M., Svensson, M. S. \& Nekaris K. A. I (2018). Comparative ecology and behaviour of eastern potto Perodicticus ibeanus and central potto P. edwardsi in Angola, Cameroon, Kenya, Nigeria, Rwanda and Uganda. Journal of East African Natural History, 107(1), 17-30.

Manley, G. H. (1974). Functions of the external genital glands of Perodicticus and Arctocebus. Prosimian biology, 313-329.

Nekaris, K. A. I. (2013). Lorisidae. In R. A. Mittermeier, A. B. Rylands, \& D. E. Wilson, eds., Handbook of the Mammals of the World: 3. Primates. Barcelona: Lynx Ediciones. pp. 210-235.

Nekaris, K. A. I., Pimley E. R. \& Ablard K. M. (2007). Predator defense by slender lorises and pottos. In S. Gursky-Doyen \& K. A. I. Nekaris, eds., Primate Anti-Predator Strategies. Springer, New York. pp. 222-240.

Nekaris, K. A. I., Starr, C. R., Collins, R. L., \& Wilson, A. (2010). Comparative ecology of exudate feeding by lorises (Nycticebus, Loris) and pottos (Perodicticus, Arctocebus). In The Evolution of Exudativory in Primates. New York: Springer. pp. 155-168.

Oates, J. F. (1984). The niche of the potto, Perodicticus potto. International Journal of Primatology, 5(1), 51.

Oates, J. F. (2011). Primates of West Africa: A Field Guide and Natural History. Conservation International, Arlington, Virginia. 
Oates, J. F. \& Ambrose, L. (2013). Arctocebus calabarensis - Calabar angwantibo. In T. M. Butynski, J. Kingdon and J. Kalina, eds., Mammals of Africa (Volume II: Primates). London: Bloomsbury Publishing. pp. 400-402.

O'Mara, M. T., Gordon, A. D., Catlett, K. K., Terranova, C. J., \& Schwartz, G. T. (2012). Growth and the development of sexual size dimorphism in lorises and galagos. American Journal of Physical Anthropology, 147(1), 11-20.

Pimley, E. R. (2002). The behavioural ecology and genetics of the potto (Perodicticus potto edwardsi) and Allen's bushbaby (Galago alleni cameronensis). PhD thesis, University of Cambridge, Cambridge, UK.

Pimley, E. R. 2009. A survey of nocturnal primates (Strepsirrhini: Galaginae, Perodictinae) in southern Nigeria. African Journal of Ecology ,47 (4), 784-787.

Pimley, E. R. \& Bearder, S. K. (2013). Perodicticus potto - potto. In T.M. Butynski., J. Kingdon and J. Kalina, eds., Mammals of Africa (Volume II: Primates,). London: Bloomsbury Publishing. pp. 393-399.

Pimley, E. R., Bearder, S. K. \& Dixson, A. F. (2005). Social organization of the Milne-Edward's potto. American Journal of Primatology, 66(4), 317-330.

Poindexter, S. A. \& Nekaris, K. A. I. (2017). Vertical clingers and gougers: Rapid acquisition of adult limb proportions facilitates feeding behaviours in young Javan slow lorises (Nycticebus javanicus). Mammalian Biology-Zeitschrift für Säugetierkunde, 87, 40-49.

Sanderson, I. T. (1940). Mammals of the north Cameroons forest area. Transactions of the Zoological Society of London, 24, 623-725.

Svensson, M. S., Nekaris, K. A. I., Bearder, S. K., Bettridge, C., Butynski, T. M., Cheyne, S. M., Das, N., de Jong, Y. A., Luhrs, A. M., Luncz, L., Maddock, S. T., Perkin, A., Pimley, E., Poindexter, S. A., Reinhardt, K. D., Spaan, D., Stark, D. J., Starr, C. R., \& Nijman, V. (2018). Sleep patterns, daytime predation, and the evolution 2 of diurnal sleep site selection in lorisiforms. American Journal of Physical Anthropology, 166(3), 563-577. 